\title{
O PROGRAMA DE EDUCAÇÃO FISCAL (PEF) E SUA CONTRIBUIÇÃO NO FORTALECIMENTO E CONSCIENTIZAÇÃO DA CIDADANIA
}

\author{
Vania Lima de Sousa Rocha ${ }^{1}$ \\ Marcel Pereira Pordeus
}

RESUMO: Este artigo é uma síntese da minha dissertação de mestrado em Ciências da Educação. Portanto, tratamos o viés da temática com apoio de outros pesquisadores, no intento de permear a formação cidadã como mote engajador social para a educação. Deste fato, sabemos que a educação é um dos pilares no processo educacional, constituindo num marco de edificação de uma consciência cidadã, proporcionando aos educandos, não somente o saber sistematizado, mas, sobretudo, o conhecimento de seus direitos e deveres. Para o exercício da cidadania fiscal, faz-se necessário que adquiram uma consciência fiscal, tendo por interesse primeiro, o bem-estar comum. Dessa forma, o tema aqui apresentado buscou investigar se a implementação do Programa de Educação Fiscal (PEF), a partir da prática pedagógica do professor, contribui para o despertar de um processo de reflexão crítica dos alunos à luz do tema transversal educação fiscal inserido de forma interdisciplinar no currículo escolar. Para tanto, o referencial teórico e metodológico embasou-se em autores como: Dallari (1998), Lima (2008), Merlo e Pertuzatti (2005), Jacomeli (2007), Yus (1998), Freire (1996) Marconi (2003) dentre outros, bem como documentos legais e manuais disponíveis na Internet. Como delimitação desse estudo foi selecionada a Escola Estadual de Ensino Profissional (EEEP) Júlio França, localizada no município de Bela Cruz - Ceará (CE), pertencente a $3^{\text {a }}$ Coordenadoria Regional de Desenvolvimento da Educação (CREDE) de Acaraú, referente as ações desenvolvidas no ano de 2016. Tendo em vista a necessidade de sensibilizar o aluno para a função socioeconômica do tributo, procuraram-se respostas para o seguinte problema que norteia essa pesquisa: Como promover a conscientização de alunos nas escolas para o fortalecimento do exercício da cidadania a partir da educação fiscal na interdisciplinaridade? Assim, o PEF vem contribuindo para que o Estado cumpra seu papel constitucional de reduzir as desigualdades sociais e ser instrumento de fortalecimento permanente da democracia, uma vez que favorece o despertar de uma consciência crítica e reflexiva acerca dos direitos e deveres do cidadão na sociedade.

Palavras-chaves: Educação Fiscal. Conscientização Tributária. Cidadania.

\footnotetext{
${ }^{\text {I }}$ Possui graduação em Serviço Social pela Universidade Estadual do Ceará (1986). Possui Especialização em Administração de Recursos Humano (1994). Atualmente é auditor fiscal da receita estadual - Secretaria da Fazenda do Estado do Ceará. E-mail: vania.lsr@hotmail.com.

${ }^{2}$ Possui graduação em Letras pela Universidade Federal do Ceará. Mestre em Planejamento e Políticas Públicas pela Universidade Estadual do Ceará.E-mail: marcel.pordeus@aluno.uece.br.
} 


\section{INTRODUÇÃO}

É sabido que o melhor agente para diminuir a desigualdade é a Educação, especialmente quando ela é democrática, visto que, independente da raça, etnia ou sexo é possível que o indivíduo modifique sua consciência através do conhecimento $e$ consequentemente seu padrão social. A educação é um dos pilares para a construção de uma consciência cidadã que supera as barreiras da desigualdade, pois não discrimina e tem como base a competência pessoal, nesse contexto vale salientar que conhecer os direitos e deveres é essencial para formação de cidadão crítico que compreende qual seu papel perante a sociedade de modo respeitoso, a fim de exigir o cumprimento de leis e contribuir de forma significativa para uma sociedade mais justa.

A maior parte da população não possui consciência sobre a importância do ensino, visto que a educação não tem sido vista como prioridade de investimentos, o papel de exigir que as contribuições estejam vinculadas aos projetos de status educacional deve partir da população, pois a mesma será beneficiada em todos os aspectos, bem como a sociedade de forma geral em assuntos de natureza fiscal, consiste no prenúncio de um despertar para o exercício da cidadania, tendo em vista que é evidente o desconhecimento do que são tributos, quais suas finalidades, como são instituídos, cobrados e aplicados.

Apesar da tributação ser altíssima, as pessoas não possuem o interesse em saber como esse dinheiro tem sido aplicado, pois sentem-se incapazes de compreender o processo complexo de distribuição de recursos, nesse sentido, há uma relevância no conhecimento ligado a situação fiscal brasileira, deve ser incentivado busca da disseminação, a fim de formar cidadãos cientes da função socioeconômica dos tributos. É essencial que o individuo tenha discernimento sobre qual a finalidade dos impostos, entender eticamente como funciona, estando sempre interessado pelo bem comum da população, esse tipo de conhecimento de âmbito escolar proporciona ao professor a oportunidade de instruir de modo eficaz a autonomia cidadã dos alunos, desafiando sempre seus alunos a buscarem uma atuação consciente dentro da comunidade onde está inserido.

A Educação Fiscal, enquanto tema transversal cria espaços para reflexões que possibilitam uma educação para a cidadania, fornecendo aos alunos o conhecimento da função socioeconômica dos tributos, induzindo-os a fiscalizarem a aplicação dos recursos advindos da arrecadação dos mesmos. Para que isto aconteça, faz-se necessário que os 
professores participem ativamente no processo de conscientização dos alunos através da inserção do tema Educação Fiscal nas diversas disciplinas.

O objetivo é incentivar os alunos sempre refletirem sobre seu papel como cidadão, visto que os indivíduos devem cooperar para tornar a sociedade um lugar mais justo, nessa perspectiva, a pesquisa se baseia na seguinte problemática: como entusiasmar a noção de alunos nas escolas, a fim de promover o exercício da cidadania ligado a educação fiscal dentro de um contexto interdisciplinar?

Como delimitação deste estudo foi selecionada a EEEP Júlio França, localizada no município de Bela Cruz - CE e pertencente a $3^{\underline{a}}$ CREDE, para realização da coleta de dados referentes às ações desenvolvidas no ano de 2016. Para tanto, foi utilizada a pesquisa bibliográfica tendo como fundamentação teórica autores que abordam o tema, como: Dallari (1998), Lima (2008), Merlo e Pertuzatti (2005), Jacomeli (2007), Freire (1996) dentre outros, Documentos Legais, manuais disponíveis na internet e a Pesquisa Qualitativa e Quantitativa do tipo participante a partir da aplicação de questionários com a coordenadora da $3^{\text {a }}$ CREDE e os professores e alunos colaboraram para a análise, além de sugestões como a de disseminar os estudo para as escolas de ensino particular.

Segundo Grzybovski e Hahn (2006), no Brasil prepondera a cultura de não pagamento de tributos devido a elevada carga tributária, com o baixo nível de retorno à sociedade e os casos de corrupção já existentes. A conscientização dos alunos quanto à importância do pagamento de tributos faz-se cada vez mais necessária, na medida em que, de acordo com Merlo e Pertuzatti (2005, p. 4), “[...] com a globalização da economia tornou-se questão de sobrevivência social a correta administração do ônus tributário e fiscal."

Conforme Castro (1978), para justificar a realização de um estudo faz-se necessário o atendimento a 03 (três) critérios, eles são distribuídos, viabilidade e importância, e a educação fiscal se encaixa nesses requisitos, pois possui pesquisas únicas e de grande valor social. Para que um povo se torne cidadão de fato, faz-se necessário que tenha conhecimento acerca da gestão dos tributos, pois somente conscientes de que os impostos pagos são a principal fonte de renda pagadora dos programas públicos, o cidadão estará apto a fiscalizar e cobrar a aplicação correta dos recursos arrecadados.

A melhor forma de abordar a educação fiscal é nas escolas, visto que possuem 
menos resistência ao aprendizado, além de ser uma estratégia que visa ao longo prazo à conscientização da sociedade como um todo, por conta disso, o aluno deve estar consciente sobre a função socioeconômica do tributo e o despertar para o acompanhamento da aplicação dos recursos públicos, almejando o benefício de toda sociedade. A abordagem do tema de tributação deve ser clara, objetivando a compreensão dos alunos, visto que possivelmente o ensino é disseminado de acordo com a empolgação que é tratado, nesse sentido, um profissional experiente é substancialmente importante, assim como o planejamento escolar ao incluir um tema de cunho político e social.

A compreensão sobre os direitos e deveres é essencial para a formação de um cidadão consciente da sua responsabilidade social, as escolas buscam construir uma sociedade mais igualitária por meio da educação, o ensino da tributação no meio estudantil auxilia na dinâmica de transformar indivíduos leigos em indivíduos conscientes do seu papel social.

Nesse contexto, a educação fiscal auxilia o aluno a criar soluções, ser mais criativo, argumentar de uma maneira eficaz diante dos problemas que enfrentam dentro das suas perspectivas comunidades, posto que, ao aprender onde o dinheiro público é empregado, o aluno a partir desse conhecimento obtém as ferramentas necessárias para que haja uma prática cidadã eficiente, pois só é possível modificar a sociedade por meio do conhecimento de como funciona a gestão de recursos públicos, nesse sentido, é importante destacar que o desempenho do cidadão na sociedade viabiliza a ampliação de jovens responsáveis

\section{A EDUCAÇÃO FISCAL E O PROCESSO DE CONSCIENTIZAÇÃO CIDADÃ}

A Educação Fiscal consiste na preparação do cidadão para compreender a atividade financeira do Estado e entender sobre a captação e aplicação dos recursos públicos. Ou seja, possibilita o processo de conscientização da sociedade de que é preciso pagar tributos para que se cumpra o que determina a Constituição, que é proporcionar o bem-estar da sociedade, e também levar a um despertar nas pessoas para que estas acompanhem a aplicação dos recursos arrecadados em busca de uma sociedade mais equilibrada, onde reine mais justiça social e menos desigualdades.

De acordo com Lima (2008, p. 72), “[...] a Educação Fiscal é o processo de acionamento da capacidade intelectual do ser humano, para conhecer as finanças públicas, 
proporcionando-lhe condições de entender, analisar e refletir sobre captação e aplicação de recursos públicos”.

Conforme o PNEF da Escola de Administração Fazendária (ESAF, 2002, p. 8):

[...] surge à discussão do tema de Educação Fiscal visando à conscientização da sociedade quanto à função do Estado de arrecadar impostos e ao dever do cidadão contribuinte de pagar o tributo. Entretanto, a Educação Fiscal não é apenas isso; é principalmente, um desafio, pois se trata de um processo de inserção de valores na sociedade, bem como, de percepção do tributo que assegura o desenvolvimento econômico e social, e com o devido conhecimento de seu conceito, sua função e sua aplicação. [...] Para que haja mudança de comportamento na sociedade com o despertar da consciência de cidadania, é necessária uma ação educativa permanente e sistemática, voltada para o desenvolvimento de hábitos, atitudes e valores. A Educação Fiscal é um trabalho de sensibilização da sociedade para a função socioeconômica do tributo. Nesta função, o aspecto econômico refere-se à otimização da receita pública, e o aspecto social diz respeito à aplicação dos recursos em benefício da população.

Lima (2008) enfatiza, que quando se vive em sociedade, o cumprimento dos deveres é essencial, pois se busca o bem comum. Quando um indivíduo deixa de cumprir uma obrigação social acaba afetando o bem-estar dos demais. Desse modo, para que se tenha a manutenção do Estado e a garantia dos direitos sociais é imprescindível que os cidadãos cumpram seus deveres fiscais. Nesse sentido, a Educação Fiscal contribui de modo relevante para a formação de um cidadão mais consciente e preparado para participar da vida pública, acompanhando a aplicação dos recursos do governo, colaborando para transparência dos serviços públicos, por fim, contribuindo para a cidadania fiscal.

\section{I A EDUCAÇÃO FISCAL COMO TEMA TRANSVERSAL: EDUCANDO PARA O EXERCÍCIO DA CIDADANIA}

A sociedade conhece superficialmente sobre os assuntos de âmbito fiscal, sabe que o imposto está presente e todos os produtos e serviços do país e que o estado incorpora esses recursos em serviços públicos, porém, educação fiscal vai além, ela tem o objetivo de instruir a população acerca das tributações de modo que torne o aluno mais consciente do seu papel fiscal e econômico, pois assim, com a participação de um tema curricular é possível exercer de modo pleno a cidadania.

A CF/88 estabeleceu uma ampla revisão do sistema educacional brasileiro. A consolidação e a especificação dos princípios constitucionais foram definidas na Lei no 9.394 de dezembro de 1996 - Diretrizes de Base da Educação Nacional. A LDBEN/96 em 
seu Art. 35 preceitua que o ensino médio, etapa final da educação básica, com duração mínima de três anos, terá como finalidades:

I - a consolidação e o aprofundamento dos conhecimentos adquiridos no ensino fundamental, possibilitando o prosseguimento de estudos;

II - a preparação básica para o trabalho e a cidadania do educando, para continuar aprendendo, de modo a ser capaz de se adaptar com flexibilidade a novas condições de ocupação ou aperfeiçoamento posteriores;

III - o aprimoramento do educando como pessoa humana, incluindo a formação ética e o desenvolvimento da autonomia intelectual e do pensamento crítico;

IV - a compreensão dos fundamentos científico-tecnológicos dos processos produtivos, relacionando a teoria com a prática, no ensino da cada disciplina (BRASIL, I996, p. I8).

Os PCNs norteiam a educação brasileira, ela organiza quais as matérias possuem uma relevância social e precisão presentes no processo estudantil dos alunos, nesse sentido, os Paramentos Curriculares Nacionais devem promover estratégias pedagógicas para desenvolver a consciência crítica do educando e a melhor forma de fazêlo é adicionar temas transversais que são importantes para que o aluno desperte sua consciência cidadã.

No Brasil, a proposta de incluir temas transversais no contexto educacional teve início a partir de 1998, após a apresentação do documento dos PCNs pelo MEC. Os temas transversais fazem parte dos PCNs, criados a partir do PNE em 1999, que possuem propostas nas quais devem ser atendidas pelas secretarias e instituições escolares, de forma impositiva e com base nisso a escola elabora seus planos de ensino. Vale destacar que com a intenção de promover temas interdisciplinares o profissional da educação busca alcançar a compreensão dos alunos para promover a reflexão profunda sobre o papel de cidadão. Nesse contexto, a proposta da transversalidade vai muito além da organização de conteúdo, fundamentando-se em torno de quatro pontos: 
[...] os temas não constituem novas áreas, pressupondo um tratamento integrado nas diferentes áreas; a proposta de transversalidade traz a necessidade de a escola refletir e atuar conscientemente na educação de valores e atitudes em todas as áreas...; a perspectiva transversal aponta uma transformação da prática pedagógica, pois rompe o confinamento da atuação dos professores às atividades pedagogicamente formalizadas e amplia a responsabilidade com a formação dos alunos...; a inclusão dos temas implica a necessidade de um trabalho sistemático e contínuo no decorrer de toda a escolaridade, o que possibilitará um tratamento cada vez mais aprofundado das questões eleitas. Por exemplo, se é desejável que os alunos desenvolvam uma postura de respeito às diferenças (BRASIL, 1998, p. 28-29).

Jacomeli (2007, p. 20) menciona que "[...] os PCNs e seus temas transversais trazem o discurso do novo representado pela produção científica, e pelo debate acadêmico atual em torno da educação mundial". Enfatiza também, que todo esse contexto acerca da temática da transversalidade, parte do princípio de que a escola é o lugar da formação do cidadão. Confirma, ainda, sua contribuição ao abordar currículo, cidadania e a fragmentação do conhecimento, quando estes são entendidos sob o ponto de vista dos PCNs:

Nos PCNs a cidadania é entendida como ativa, que tem como ponto de partida a compreensão do cidadão como portador de direitos e deveres, mas que também o vê como criador de direitos, participando da gestão pública [...] os PCNs sugerem, ao discutir a justificativa da inclusão desses temas no currículo, que a escola está sendo incapaz de formar indivíduos para exercerem a cidadania ativa. Esse diagnóstico tem como pressuposto que o currículo organizado pela antiga estruturação disciplinar é o responsável pelo fracasso da escola [...] É aí que entram, então, os temas transversais, temas sociais importantes para o atual momento histórico, segundo os PCNs, para se consubstanciar em mecanismos integradores das diversas disciplinas, superando a fragmentação do conhecimento escolar. A justificativa teórica para essa superação encontra-se na discussão em torno do embate posto pelos defensores da chamada pós-modernidade (JACOMELI, 2007, p. 20).

Nesse contexto, é possível perceber que os temas transversais produzem de maneira positiva o debate acerca da sociedade que alunos estão inseridos, a fim de superar o ensino tradicional e promover assuntos que tenham relevância no cotidiano das pessoas.

Os PCNs elegem quatro critérios para a inserção de um tema transversal no currículo escolar: urgência social, abrangência nacional, possibilidade de ensino e aprendizagem e favorecimento da compreensão da realidade e participação social. A educação fiscal vem contemplar todos esses critérios.

No que tange a urgência social, é possível perceber a importância da Educação Fiscal na vida cotidiana da população, que diariamente contribui sem compreender como é o processo financeiro de investimentos governamentais na promoção de bem-estar público. 
Em relação à abrangência nacional, trata-se de um tema de destaque para o equilíbrio socioeconômico e a viabilidade das políticas públicas dos entes federativos: União, Estados, Municípios e DF.

No que se refere à possibilidade de ensino e aprendizagem, a educação fiscal adequa-se perfeitamente, tendo em vista a expressiva mudança curricular e a maior participação do aluno na vida social. Finalmente, quanto a favorecer a compreensão da realidade e a participação social, a Educação Fiscal é um tema que estimula professores e alunos a desenvolver uma reflexão crítica frente aos problemas sociais, econômicos e culturais e os impulsiona a participar das decisões políticas de forma mais eficaz.

E é neste contexto que a temática 'Educação Fiscal' ganha importância como tema transversal a ser amplamente discutido e inserido nas escolas de nosso país, conforme averiguado a seguir:

[...] existem experiências municipais de orçamento participativo, nas quais os cidadãos, por meio de associações ou de forma individual, discutem as prioridades e determinam como esse dinheiro será aplicado. É importante estar atento ao destino que o administrador dá aos impostos arrecadados e ao recolhimento do imposto que o comerciante, o industrial ou o prestador de serviço deve efetuar. É preciso procurar saber quanto é recolhido de imposto, qual sua destinação, quem deveria pagar mais ou menos, contribuindo para o desenvolvimento das questões tributárias, participando da elaboração do orçamento público, discutindo suas prioridades e controlando sua execução (BRASIL,1998, p. 356-357).

A introdução de temas transversais no currículo cria espaços para reflexões que possibilitam uma educação para a cidadania. Essa prática implica num posicionamento diferenciado do professor frente ao conhecimento que se propõe ensinar. A Educação Fiscal, enquanto tema transversal, alarga o entendimento das questões tributárias, fiscais e orçamentárias, levando o indivíduo e a coletividade a construírem valores, conhecimentos, atitudes, habilidades e competências. O item a seguir abordará a contribuição do professor neste procedimento que visa o despertar de um processo de reflexão crítica nos alunos.

\subsection{O PAPEL DO PROFESSOR NO CONTEXTO TRANSVERSAL: AGENTE TRANSFORMADOR}

A escola é compreendida como agente de transformação que estabelece com a comunidade sua principal parceria para o desenvolvimento de projetos pedagógicos articulados com questões sociais relevantes. Desse modo, cabe a escola trabalhar temas transversais que facilitem, fomentem e integrem as ações de modo contextualizado através 
da interdisciplinaridade e transversalidade, buscando não fragmentar o conhecimento em blocos rígidos, para que a Educação realmente se constitua no meio de transformação social.

Nesse contexto, surge a figura do professor enquanto facilitador do processo de ensino-aprendizagem, levando os alunos a construírem significados e conferirem sentido àquilo que aprenderem de modo a levá-los a interferirem na realidade para transformá-la. O saber outrora fragmentado abre-se para acolher novos temas que despontam na sociedade e que precisam ser contextualizados, levando o educando a tomar consciência das questões relativas à realidade em que vive. Esse despertar viabiliza a formação de um senso crítico responsável por fazê-lo entender a importância de sua participação e de seu engajamento em ações que promovam o bem-estar de todos.

Conforme já foi visto, com a reforma do sistema educacional temas transversais foram incluídos no currículo. Com isso, o educador deixa de ser um mero executor de orientações curriculares e reprodutor de conhecimentos e experiências, e passa a refletir sobre a necessidade de uma ação pedagógica inovadora, na qual o professor faça brotar a curiosidade de acompanhar ações de desenvolvimento das atividades, facilitar e mediar na construção ativa do conhecimento do aluno.

Nesse sentido, não há necessidade de parar a programação curricular, o professor pode abordar dentro da aula diversos temas relevantes ligados às questões econômicas, políticas e sociais presentes no cotidiano do aluno. $\mathrm{O}$ professor deve dedicar um planejamento dinâmico com relação a área de Educação Fiscal para que haja sintonia entre a teoria e prática, buscando sempre a pluralidade de conhecimentos, visto que os temas são transversais e podem estar ligados a vários aspectos da prática cidadã.

Segundo Freire (1996), ensinar não é transmitir conhecimento, mas criar possibilidades para sua própria produção, sob essa ótica o professor deve estimular os alunos a superarem as barreiras de perspectiva restritiva e conseguir promover o protagonismo cidadã. Conforme Libâneo (20II), o professor necessitará ajustar sua didática as novas realidades da sociedade, utilizando métodos em que ele tenha a função de mediador e o aluno seja o pensante crítico. ativa dos conteúdos como desenvolvimento da capacidade cognitiva e afetiva dos alunos visando à formação de estruturas próprias de conhecimento, mediante a condução pedagógica do professor que disporá de práticas de ensino intencionais e 
sistemáticas de promover o "ensinar a aprender a pensar" (LIBÂNEO, 20II p. 23).

O papel do profissional da educação é muito importante, pois por meio dele é possível incentivar os educandos a promover projetos educacionais que irão desenvolver soluções de forma ética, as questões urgentes da sociedade. De acordo com os PCNs:

\begin{abstract}
Propor que a escola trate questões sociais na perspectiva da cidadania coloca imediatamente a questão da formação dos educadores e de sua condição de cidadãos. Para desenvolver sua prática os professores precisam também desenvolver-se como profissionais e como sujeitos críticos na realidade em que estão, isto é, precisam poder situar-se como educadores e como cidadãos, e, como tais, participantes do processo de construção da cidadania, de reconhecimento de seus direitos e deveres, de valorização profissional (BRASIL, 1997, p. 38).
\end{abstract}

Fica claro, portanto, que o professor deixa de ser reprodutor de conceitos ou ideias para tornar-se um mediador entre o conhecimento e o educando, e que nesse processo ambos se complementam, pois também aprendem quem ensina e ensina quem aprende. O professor tem o papel de incentivar os alunos a pensarem de modo investigativo, ou seja, avaliando e refletindo sobre as questões tributárias do país, de modo crítico e analítico, nesse sentido, é essencial que haja parceria entre aluno e professor, ao que elevará o grau de conhecimento da turma.

\title{
CONCLUSÃO
}

A educação deve se constituir como um marco de edificação de uma consciência cidadã, proporcionando a todos o conhecimento dos seus direitos e deveres, bem como a compreensão de que o respeito e o cumprimento de ambos contribuem para uma sociedade mais justa e equilibrada. A partir deste princípio, apresentamos como objetivo geral desta pesquisa de Mestrado o de verificar a contribuição do PEF para o fortalecimento e conscientização cidadã, a partir da prática pedagógica das escolas sendo traçadas algumas variáveis que subsidiaram os resultados.

É notória a ausência de uma efetiva formação cívica em matéria fiscal, principalmente no ensino básico, ponto de partida para a consolidação do caráter do cidadão, e que o ensino da História brasileira nos mostra a ausência de uma mentalidade pautada na cidadania fiscal. Os livros e manuais que relatam os feitos do Brasil colonial, imperial e mesmo republicano, descrevem a malversação do dinheiro público pelos agentes estatais, dando ênfase às histórias de sonegação, contrabando e descaminho. Raramente, tais livros tecem considerações sobre os direitos de cidadania e os deveres necessários para 
garanti-los e exercitá-los enquanto antídoto possível para tais comportamentos.

A partir dos teóricos e legislações que subsidiaram a pesquisa, e, apesar das limitações identificadas, considera-se que o estudo realizado permitiu conhecer melhor as ações que estão sendo implementadas no âmbito educacional da $3^{\text {a }}$ CREDE, em especial a EEEP Júlio França, apresentando resultados ainda não condizentes com o ideal, mas que trarão benefícios aos alunos que, no futuro, serão cidadãos trabalhadores e conscientes de seus direitos e deveres tributários.

Mediante a relevância da pesquisa foi possível concluir que os Cursos presenciais de educação fiscal e cidadania e os Cursos de Disseminadores de Educação Fiscal estão formando docentes em educação fiscal, a fim de serem disseminadores dos conteúdos relativos às matérias fiscal e tributária nos espaços escolares, oferecendo informações teóricas e práticas que venham a estabelecer a interface entre o processo de ensino aprendizagem e a temática da educação fiscal, a partir de análise e construção das atividades didáticas, fortalecendo assim um ensino mais eficaz.

Desta forma, concluímos que o desenvolvimento do PEF contribui para que o Estado cumpra seu papel constitucional de reduzir as desigualdades sociais e ser instrumento de fortalecimento permanente da democracia. As pesquisas ligadas ao tema mostrou que ao inserir a educação fiscal como currículo dentro da sala de aula, faz com que os alunos se tornem mais ativistas na questão de impacto social, pois o individuo torna-se mais crítico e emerge a função socioeconômica do contribuinte, como pauta importante nas reflexões estudantis, discussões que se relacionam com a tributação, tem em sua maioria o assistencialismo como dever do estado.

Consideramos que muito há ainda o que percorrer no campo da investigação nesta temática, recomendando, portanto, que o PEF seja implantado nas demais CREDEs/Escolas do Ceará, como veículo de disseminação da educação fiscal, a fim de desenvolver no jovem aluno uma consciência crítica e reflexiva, tornando-o cada vez mais cônscio da função socioeconômica do tributo, conhecedor dos seus direitos e deveres, bem como de servir como instrumento na difusão de informações permanentes possibilitando, portanto, a construção para uma prática cidadã. 


\section{REFERÊNCIAS}

BRASIL. Código Tributário Nacional (CTN). Lei no 5.172, 2. ed., Brasília: Senado Federal, Subsecretaria de Edições Técnicas, 2012.

BRASIL. Constituição da República Federativa do Brasil: promulgada em 5 de outubro de 1988. Disponível em: constituicao/constituicao.htm. Acesso em: I2 jun. 2017.

BRASIL. Ministério da Fazenda. Escola de Administração Fazendária - Programa Nacional de Educação Fiscal-PNEF, educação fiscal no contexto social/Programa Nacional de Educação Fiscal (série Educação Fiscal, cadernoı, 5. ed., Brasília: ESAF 2014.

BRASIL. Programa Nacional de Educação Fiscal: Educação Fiscal no contexto social (Série Educação Fiscal. Cadernos). Brasília: Ministério da Fazenda; Ministério da Educação. Escola de Administração Fazendária, 2004. Disponível em: http://www.esaf.fazenda.gov.br/ parcerias/ educacao-fiscal/caderno/caderno_I.pdf. Acesso em: 30 maio 2017 .

BRASIL. Programa de Educação Fiscal (PEF), 2009. Disponível em: https://www.sefaz.ce.gov.br/Content/aplicacao/EducacaoFiscal/principal/gerados/relato rios.asp? categoria=3. Acesso em: 20 jun. 2017.

CASTRO, Claudio de Moura. A prática da pesquisa. São Paulo: McGraw-Hill do Brasil. 1978.

CEARÁ, Decreto no 25.326/98. Institui o Programa Estadual de Educação Tributária PET no âmbito do Estado do Ceará.

CEARÁ. Decreto no $\mathbf{2 8 . 9 0 0 / 2 0 0 7 . ~ C r i a c ̧ a ̃ o ~ d a ~ C e ́ l u l a ~ d e ~ E d u c a c ̧ a ̃ o ~ F i s c a l , ~ n o ~ a ̂ m b i t o ~ d a ~}$ Coordenadoria de Administração Tributária passando a ser chamado Programa de Educação Fiscal- PEF

DALLARI, Dalmo. Direitos Humanos e Cidadania. São Paulo: Moderna, 1998. 
FREIRE, Paulo. Saberes necessários para prática educativa. São Paulo: Paz e terra, 1996.

GRZYBOVSKI, D; HAHN, T. G. Educação fiscal: premissa para melhor percepção da questão tributária. Revista de Administração Pública, v. 40, n. 5, p. 84I-864, 2006.

JACOMELI, M. R. M. PCNs e Temas Transversais - análise histórica das políticas educacionais brasileiras. Campinas-SP. Alínea, 2007.

LIBÂNEO, José Carlos. Adeus professor, adeus professora? - Novas exigências educacionais e profissão docente. São Paulo, Cortez, 20II

LIMA, Aldo José Rodrigues. Políticas Educacionais e Ensino Médio da Literatura brasileira. Dissertação de Mestrado. Recife Universidade Federal de Pernambuco. Centro de Educação.2008

MERLO, Roberto Aurélio; PERTUZATTI, Elizandra. As melhores práticas de controladoria: o balanced scorecard como ferramenta de gestão. REVISTA CATARINENSE DA CIÊNCIA CONTÁBIL. [S.I], v. 6, n.I8, o9-24, out. 2011. Disponível em: http://revista.crcsc.org.br/index.php/CRCSC/article/view/ro53987. Acesso em: io fev. 2017. 